\title{
Subcorneal pustular dermatosis
}

INSERM

\section{Source}

INSERM. (1999). Orphanet: an online rare disease and orphan drug data base. Subcorneal pustular dermatosis. ORPHA:48377

Subcorneal pustular dermatosis is a rare, benign, chronic disease characterized by sterile pustular eruption, typically involving the flexural sites of the trunk and proximal extremities. 